\title{
Prescription Pattern of Proton Pump Inhibitors at Hospital Admission and Discharge
}

\author{
Verónica Gamelas ${ }^{a}$ Vera Salvado $^{\mathrm{b}}$ Luís Dias $^{\mathrm{b}}$ \\ ${ }^{a}$ Gastrenterologia, Centro Hospitalar Lisboa Central, Lisbon, Portugal; bedicina Interna, Centro Hospitalar Lisboa \\ Central, Lisbon, Portugal
}

\section{Keywords}

Proton pump inhibitors · Indications · Overuse · Prescription

\section{Abstract}

Background: Proton pump inhibitors (PPI) have reportedly been used in inappropriate clinical settings, often leading to an increased risk of adverse effects, drug interactions, and costs. Aim: The aim of this study was to evaluate the adequacy of PPI prescription in an internal medicine ward. Methods: The discharged home inpatients of a segment in the medicine department of a central hospital in the first trimester of 2017 were evaluated; those who died or were transferred to another unit were excluded. Data on gender, age, admission, and discharge therapy and diagnoses which could support PPI use were collected from clinical records. Statistical analysis was performed using Microsoft Excel $2013^{\circledR}$ and IBM SPSS Statistics $20^{\circledR}$. Results: A total of 318 hospitalizations were included, corresponding to 301 patients; 171 (56.8\%) were female and the average age was $75.4 \pm 14.6$ years. Among the 318 hospitalizations, 148 patients (46.5\%) were on PPI at admission and 175 (55\%) at discharge, the majority of them without indication ( $n=91,61.5 \%$ vs. $n=109,62.3 \%$ ). The main inappropriate indication was anticoagulation alone ( $n=33,36.3 \%$ vs. $n=43,39.4 \%$ ). There was indication for PPI

\section{KARGER}

E-Mail karger@karger.com www.karger.com/pjg
(C) 2018 Sociedade Portuguesa de Gastrenterologia Published by S. Karger AG, Basel

Karger

Open access

This article is licensed under the Creative Commons AttributionNonCommercial-NoDerivatives 4.0 International License (CC BYNC-ND) (http://www.karger.com/Services/OpenAccessLicense). Usage and distribution for commercial purposes as well as any distribution of modified material requires written permission. therapy in 93 (29.2\%) of the cases at admission and 111 (34.9\%) at discharge, mostly for prophylaxis of gastrointestinal bleeding in high-risk patients ( $n=82,88.2 \%$ vs. $n=96$, $86.5 \%)$. Among those with indication, 57 (61.3\%) were medicated at admission versus 66 (59\%) at discharge. The association between PPI therapy and an indication for its prescription was lost by the time of discharge $(p=0.245)$. Conclusions: PPI prescription is not in agreement with existing recommendations, which is why it should be revised at hospital discharge. The primary indication for PPI therapy is the prophylaxis of gastrointestinal bleeding in high-risk patients and the main inappropriate indication is prophylaxis in lowrisk patients. A large proportion of the patients indicated for $\mathrm{PPI}$ use were discharged without prescription.

\footnotetext{
(C) 2018 Sociedade Portuguesa de Gastrenterologia Published by S. Karger AG, Basel
}

\section{Padrão de prescrição de inibidores da bomba de protões no momento da admissão e da alta hospitalar}

\section{Palavras Chave}

Inibidores da bomba de protões - Indicações .

Sobreutilização · Prescrição
Dr. Verónica de Novais Paiva de Mourão Gamelas Rua do Mato da Mina, $\mathrm{n}^{\circ} 77$, Sintra PT-2710-695 Lisbon (Portugal)

E-Mail veronicagamelas@ gmail.com 


\section{Resumo}

Introdução: Os inibidores da bomba de protões (IBP) têm sido utilizados em situações sem indicação, com aumento do risco de efeitos adversos, interações medicamentosas e custos. Objetivo: Avaliar a pertinência da prescrição dos IBP numa enfermaria de Medicina Interna. Métodos: Foram avaliados os internamentos de uma Enfermaria de Medicina de um Hospital Central, cuja alta ocorreu para o domicílio no $1^{\circ}$ trimestre de 2017; foram excluídos aqueles que morreram ou foram transferidos. Foram recolhidos os seguintes dados do processo clínico: género, idade, terapêutica à admissão e à alta; antecedentes pessoais ou diagnósticos que pudessem sustentar a toma de IBP. A análise estatística foi realizada através do Microsoft Excel $2013^{\circledR}$ e IBM SPSS Statistics $20^{\circledR}$. Resultados: Foram incluídos 318 internamentos, correspondentes a 301 doentes, 171 (56.8\%) do género feminino, com uma idade média de $75.4 \pm 14.6$ anos. Nos 318 internamentos, 148 doentes (46.5\%) estavam sob IBP à admissão e 175 (55\%) à alta, a maioria ( $n=91,61.5 \%$ vs. $n=109,62.3 \%$ ) sem indicação. A principal indicação inapropriada foi a anticoagulação isolada ( $n=33,36.3 \%$ vs. $n=43,39.4 \%$ ). Houve indicação para uso de IBP em 93 (29.2\%) casos à admissão e 111 (34.9\%) à alta, na maioria ( $n=82,88,2 \%$ vs. $n=96,86.5 \%)$ para profilaxia de hemorragia gastrointestinal em doentes de alto risco. Dos doentes com indicação, apenas 57 (61.3\%) estavam medicados à admissão versus 66 (59\%) à alta. Houve uma perda de associação entre a terapêutica com IBP e a existência de indicação para a sua prescrição no momento da alta ( $p=0.245)$. Conclusões: A prescrição de IBP é incongruente com as recomendações, pelo que esta deve ser revista no momento da alta. A principal indicação para IBP é a profilaxia de hemorragia gastrointestinal em doentes de alto risco e a principal indicação inapropriada é a sua profilaxia em doentes de baixo risco. Uma proporção significativa de doentes com indicação para IBP teve alta sem a sua prescrição.

(c) 2018 Sociedade Portuguesa de Gastrenterologia Publicado por S. Karger AG, Basel

\section{Introduction}

Omeprazole was the first proton pump inhibitor (PPI) discovered and has been available in Europe for acid suppression since 1988. Subsequently, other drugs have been identified and several alternatives are currently available: lansoprazole, pantoprazole, rabeprazole, dexlansoprazole, and esomeprazole [1].

PPI at Hospital Admission and Discharge
Compared with histamine-2 receptor antagonists, these drugs are more powerful in decreasing gastric acidity, which has revolutionized the treatment of peptic ulcer disease and gastroesophageal reflux disease (GERD). PPI have also assumed a leading role in the eradication of $\mathrm{He}$ licobacter pylori, pathological hypersecretion (such as Zollinger-Ellison syndrome), and prophylaxis of gastrointestinal bleeding in high-risk patients.

However, supported by its excellent effectiveness and safety profile, there has been an expansion of its use in inappropriate clinical contexts, such as the prophylaxis of gastrointestinal bleeding in low-risk patients and usage for longer than indicated. This increased prescription of PPI, allied to its growing accessibility due to the emergence of generics and over-the-counter availability, places PPI amongst the most selling drugs in the world.

However, its use is not innocuous and several studies document potential adverse effects such as acute interstitial nephritis, gastric polyposis, vitamin $\mathrm{B}_{12}$ and magnesium deficiency, Clostridium difficile infection or bacterial overgrowth in cirrhotic patients with an increased risk of spontaneous bacterial peritonitis [2, 3]. Additional studies are still needed to clarify the relationship between the use of PPI and certain adverse effects and, therefore, its prescription should not be discouraged when indicated [4]. It should also be noted that there has been an expansion of PPI prescription to all age groups, including polymedicated elderly, thus increasing the risk of drug interactions. Such overuse of PPI has a financial impact on patients and public health spendings alike.

\section{Aim}

The aim of this study was to evaluate the adequacy of PPI prescription in an internal medicine ward, comparing its use at admission and discharge.

\section{Methods}

A list of patients discharged from the Functional Unit of Medicine 1.2 between January 1 and March 31, 2017 was obtained. The study included all the patients discharged home and excluded those who died or who were transferred to another hospital unit. Discharge letters were consulted to collect the following data: (1) age and gender; (2) pre-hospitalization and discharge medication (PPI, anti-platelet drugs, anticoagulants, corticosteroids, nonsteroidal anti-inflammatory drugs [NSAIDs], and selective cyclooxygenase [COX-2] inhibitors); (3) personal history or recent diagnosis that supported the use of PPI. A history of peptic ulcer documented on upper digestive endoscopies was sought in the patient's

GE Port J Gastroenterol 2019;26:114-120 115 
Table 1. Indications for use of PPI according to the Food and Drug Administration (FDA) and the National Institute for Clinical Excellence (NICE) [5-13]

- Erosive esophagitis - healing and maintenance therapy

- GERD and its clinical manifestations (including nonerosive disease, symptomatic control*, esophageal strictures, Barrett's esophagus)

- HP eradication in combination with antibiotics

- Short-term treatment of HP-negative peptic ulcers and maintenance therapy

- Treatment of gastric ulcers associated with NSAIDs

- NSAID-induced dyspepsia

- Reduction of risk of gastric ulcers in NSAID users with a high

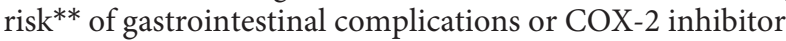
users with previous history of upper gastrointestinal bleeding

- Gastric pathological hypersecretion (Zollinger-Ellison disease)

- Critically ill patients, under prolonged mechanical ventilation

- Short-term treatment* of patients with functional dyspepsia

* 4-8 weeks of treatment, followed by minimum effective dose or use on demand, if symptoms persist. ${ }^{* *}$ Age $>65$ years or concomitant use of corticosteroids, antiplatelet agents, or anticoagulants or previous history of peptic ulcer disease.

electronic record. The indications considered valid are listed in Tables 1 and 2 .

A $\chi^{2}$ test was used to evaluate the association between variables and it was considered statistically significant when $p<0.05$. Statistical analysis was performed using Microsoft Excel $2013{ }^{\circledR}$ and IBM SPSS Statistics $20^{\circledR}$.

\section{Results}

From January 1 to March 31, 2017, there were 384 discharges from the Functional Unit of Medicine 1.2. Among those patients, $318(82.8 \%)$ were discharged home, 50 (13\%) died, and 16 (4.2\%) were transferred to another hospital unit. A total of 301 patients were included in the study, since 14 of them had more than 1 hospitalization within this period of time.

Demographically, 171 patients $(56.8 \%)$ were female and $130(43.2 \%)$ were male. The patients' ages ranged from 19 to 102 , with an average age of $75.4 \pm 14.6$.

Of the 318 cases analyzed, 148 (46.5\%) were on PPI therapy at admission, most of them under omeprazole $(n=66,44.6 \%)$, followed by pantoprazole $(n=54,36.5 \%)$; 175 patients $(55 \%)$ were discharged with a PPI prescription, most of them with pantoprazole $(n=87,49.7 \%)$, followed by omeprazole $(n=56,32 \%)$. Lansoprazole was
Table 2. Other valid indications for PPI therapy $[8,12,14,15]$

- Reduction of risk of gastric ulcers in high-risk patients* treated with antiplatelet agents

- Eosinophilic esophagitis

- Steatorrhea refractory to enzyme replacement therapy in patients with exocrine pancreatic insufficiency

- Prior to upper gastrointestinal endoscopy for upper gastrointestinal bleeding and following endoscopic therapy in patients with high-risk ulcers**

* Age $>65$ years or concomitant use of corticosteroids or anticoagulants or previous history of peptic ulcer disease. ${ }^{* *}$ Forrest classification Ia, Ib, IIa, and IIb.

Table 3. Likely causes for PPI use in patients with no obvious indication

\begin{tabular}{lrrrr}
\hline & $\begin{array}{l}\text { Admission } \\
(n=91)\end{array}$ & $\begin{array}{l}\text { Discharge } \\
(n=109)\end{array}$ \\
\hline Anticoagulation* & 33 & $36.3 \%$ & 43 & $39.4 \%$ \\
Corticotherapy* & 9 & $9.9 \%$ & 9 & $8.3 \%$ \\
Anticoagulation and corticotherapy* & & & 9 & $8.3 \%$ \\
Gastritis & 10 & $11 \%$ & 8 & $7.3 \%$ \\
Previous history of ulcer* & 5 & $5.5 \%$ & 8 & $7.3 \%$ \\
Chronic hepatic disease & 4 & $4.4 \%$ & 6 & $5.5 \%$ \\
Antiplatelet monotherapy* & 2 & $2.2 \%$ & 5 & $4.6 \%$ \\
NSAID* & & & 1 & $0.9 \%$ \\
No perceptible cause & 28 & $30.8 \%$ & 20 & $18.3 \%$ \\
\hline
\end{tabular}

* Without any concomitant risk factors to justify PPI use.

preferred in $5(3.4 \%)$ patients at admission and $3(1.7 \%)$ at discharge. None of the patients included in this study had a rabeprazole prescription at admission or discharge. Esomeprazole had intermediate use rates $(n=23,15.5 \%$ at admission vs. $n=29,16.6 \%$ at discharge).

Ninety one $(61.5 \%)$ of the PPI users on admission had no indication for this therapy, according to the indications expressed in Tables 1 and 2. While analyzing these prescriptions we found several likely justifications for this, which are shown in Table 3.

On the other hand, of all 318 analyzed cases, 93 (29.2\%) had an indication for PPI use on admission, most of them $(n=82,88.2 \%)$ for gastrointestinal bleeding prophylaxis. The distribution of prophylactic indications for PPI use was as follows: 78 (95.1\%) patients were older than 65 years and were under concomitant antiplatelet therapy, 
Table 4. Distribution of indications for PPI at admission and discharge

\begin{tabular}{|c|c|c|c|c|}
\hline \multirow[t]{2}{*}{ Indication } & \multicolumn{2}{|c|}{ Admission } & \multicolumn{2}{|c|}{ Discharge } \\
\hline & $n$ & $\% * *$ & $n$ & $\% * *$ \\
\hline Prophylaxis* & 82 & $88.2 \%$ & 96 & $86.5 \%$ \\
\hline NSAIDs & 3 & $3.7 \%$ & 0 & $0.0 \%$ \\
\hline Age $>65$ & 3 & $3.7 \%$ & 0 & $0.0 \%$ \\
\hline Previous history of ulcer & 1 & $1.2 \%$ & 0 & $0.0 \%$ \\
\hline Antiplatelet drugs & 79 & $96.3 \%$ & 96 & $100.0 \%$ \\
\hline Age $>65$ & 78 & $95.1 \%$ & 95 & $99.0 \%$ \\
\hline Corticosteroids & 1 & $1.2 \%$ & 7 & $7.3 \%$ \\
\hline Anticoagulants & 12 & $14.6 \%$ & 10 & $10.4 \%$ \\
\hline Previous history of ulcer & 4 & $4.9 \%$ & 4 & $4.2 \%$ \\
\hline Therapeutic & 11 & $11.8 \%$ & 15 & $13.5 \%$ \\
\hline GERD & 9 & $81.8 \%$ & 11 & $73.3 \%$ \\
\hline Dyspeptic symptoms & 2 & $18.2 \%$ & 3 & $20.0 \%$ \\
\hline Ulcer healing & 0 & $0.0 \%$ & 1 & $6.7 \%$ \\
\hline HP eradication & 0 & $0.0 \%$ & 1 & $6.7 \%$ \\
\hline Total & 93 & $100.0 \%$ & 111 & $100.0 \%$ \\
\hline
\end{tabular}

* Excluding patients with simultaneous indication for therapeutic PPI. ** Percentage of total patients indicated for prophylactic or therapeutic PPI (each patient may be included in more than one subindication, as described in the text).

12 of whom (14.6\%) were also anticoagulated and 4 (4.9\%) had a previous history of ulcer; 1 patient $(1.2 \%)$ was under simultaneous antiplatelet and corticosteroid therapy; 3 patients (3.7\%) were both older than 65 and under NSAID therapy, 1 of whom (1.2\%) had a previous history of ulcer. Eleven patients $(11.8 \%)$ had indication for therapeutic PPI use: 9 of these (81.8\%) due to GERD and $2(18.2 \%)$ due to dyspeptic symptoms. The indications for PPI on admission are summarized in Table 4. Among the patients with valid indications for PPI use on admission, only 57 (61.3\%) were under PPI therapy.

Regarding PPI users on discharge, 109 (62.3\%) had no indication for this therapy as defined by the FDA and NICE, meaning that PPI use was indicated in only 66 $(37.7 \%)$ of the analyzed patients. The most plausible justifications for the use of PPI with no indication are described in Table 3.

Similarly, by analyzing all hospitalizations, we found that 111 patients $(34.9 \%)$ had indication for PPI at discharge, 96 of them (86.5\%) with prophylactic intent. The distribution of prophylactic indications for PPI use at discharge is summarized as follows: 95 patients (99\%) were
Table 5. Distribution of patients by use of PPI, according to indication for their prescription, at admission

\begin{tabular}{lccc}
\hline & \multicolumn{2}{c}{ PPI use at admission } & Total \\
\cline { 2 - 3 } & no & yes & \\
\hline PPI indication at admission & & \\
$\quad$ No & 134 & 91 & 225 \\
Yes & 36 & 57 & 93 \\
\hline Total & 170 & 148 & 318 \\
\hline
\end{tabular}

Table 6. Distribution of patients by use of PPI, according to indication for their prescription, at discharge

\begin{tabular}{lccc}
\hline & \multicolumn{2}{c}{ PPI use at discharge } & \multirow{2}{*}{ Total } \\
\cline { 2 - 3 } & no & yes & \\
\hline PPI indication at discharge & & & \\
$\quad$ No & 98 & 109 & 207 \\
$\quad$ Yes & 45 & 66 & 111 \\
\hline Total & 143 & 175 & 318 \\
\hline
\end{tabular}

over 65 years old and were under antiplatelet therapy, 10 (10.4\%) of whom were also anticoagulated, 6 (6.3\%) were concurrent corticosteroid users, and 4 (4.2\%) had a previous history of ulcer; 1 patient (1\%) was under concomitant antiplatelet and corticosteroid drugs (without age as a risk factor). Of the 15 patients (13.5\%) with indication for therapeutic PPI, 11 (73.3\%) had GERD, 2 (13.3\%) had dyspeptic symptoms, 1 (6.7\%) was undergoing Helicobacter pylori eradication therapy for dyspeptic symptoms, and 1 (6.7\%) was on ulcer therapy. Indications for PPI at discharge are summarized in Table 4. Among patients with indication for PPI at discharge, 66 (59\%) were under PPI therapy.

Tables 5 and 6 show the distribution of patients according to whether or not they were undergoing PPI, taking into account the existence of an indication for its prescription, at admission and discharge.

Although there is a correlation between PPI therapy at admission and an indication for its prescription $\left(\chi^{2}(1)=\right.$ $11.493, p=0.001)$, this is not carried on to discharge $\left(\chi^{2}(1)=1,351, p=0.245\right)$.

During hospitalization, PPI was suspended in 17 patients $(5.3 \%)$, correctly in 13 cases $(76.5 \%)$ but improp- 
erly in 4 patients (23.5\%) who had an indication for PPI on discharge due to antiplatelet therapy associated with other risk factors. On the other hand, PPI was introduced in 44 patients (13.8\%), with no indication in most of them ( $n=27,61.4 \%$ vs. $n=17,38.6 \%)$.

\section{Discussion}

This study included 301 patients who represented the population of an internal medicine ward, with a slight predominance of women (56.8\%) and an average age of 75 . This sample only concerns a restricted period of time and a single hospital unit, which limits the extrapolation of data to other sites or longer periods of time. As a retrospective analysis, data was obtained through records with possible errors or omissions of risk factors or therapeutic indications, which could have led to statistical bias.

Our analysis focuses on hospitalization episodes rather than patients, who may have been considered more than once. In fact, PPI prescription indications are dynamic and should be evaluated periodically in order to adjust prescription accordingly. Supported by this, the authors found no significant difference between analyzing two different patients or the same patient at different moments.

The indications for PPI use considered in this analysis include both a group of well-accepted indications as well as others considered valid by experts but not yet covered by current recommendations. Even though other indications are emerging, scientific evidence is still lacking, and therefore, further research is required. Examples of such indications are: treatment or prevention of chemotherapy-induced GERD and gastroduodenal ulceration in cancer patients; dual antiplatelet therapy or anticoagulation without other risk factors; use of selective serotonin reuptake inhibitors; use of COX-2 inhibitors in high-risk patients due to other reasons than previous gastrointestinal bleeding; and patients on high doses of NSAID even without other risk factors $[13,15]$.

Omeprazole and pantoprazole were shown to be the most prescribed PPI, and it seems there is a preference for pantoprazole at hospital discharge. On the other hand, lansoprazole and rabeprazole were rarely used. Nevertheless, it should be noted that rabeprazole and pantoprazole, due to their lower dependence on cytochrome CYP2C19 metabolism, may be preferable in an elderly and polymedicated population as it would decrease the likelihood of drug interactions.
Our analysis shows that nearly half of the patients (46.5\% at admission and 55\% at discharge) were under PPI therapy, which was not indicated in more than half of them (61.5\% at admission and $62.3 \%$ at discharge). These results are in agreement with similar studies carried out elsewhere $[9,16,19]$. Overprescription of PPI in this group of patients appears to be mainly due to ulcer prophylaxis in low-risk patients, especially in anticoagulated patients (36.3 and $39.4 \%$ at admission and discharge, respectively) or patients undergoing corticosteroid therapy (9.9\% at admission and $16.5 \%$ at discharge). In contrast to antiplatelet drugs, anticoagulants do not affect gastric protection mechanisms and may only increase bleeding risk in patients with prior gastrointestinal injury. The use of PPI in anticoagulated patients without concomitant use of NSAIDs or antiplatelet agents is therefore not recommended. In the same way, unlike NSAIDs, whose association with gastric mucosal lesion is well known, corticosteroid gastrotoxicity is not well documented and is inconsistent among different studies [2023]. As a result, the use of PPI in the absence of NSAIDs and/or concomitant antiplatelet therapy is also not recommended. It should also be noted that there is recent evidence of an increased risk for hepatic encephalopathy in cirrhotic patients using PPI [24]. Such patients are often incorrectly prescribed PPI for gastritis or chronic liver disease.

It was decided not to address patients' anemia in the present study given its multiple etiologies and since it was not possible to establish an association between its presence and PPI prescription rationale. However, similar studies suggest anemia to be an important factor for inappropriate prescription of PPI [16].

It was observed that about one-third of patients (29.2\% at admission and $34.9 \%$ at discharge) were eligible for PPI therapy. Among them, only 60\% (61.3 and 59.5\% at admission and discharge, respectively) were prescribed a PPI. This shows that, in addition to an expansion of PPI use into inappropriate clinical settings, there is also an undermedication of patients with well-established indications for PPI. The vast majority of these patients had indication for ulcer prophylaxis (88.2\% at admission and $86.5 \%$ at discharge), mainly due to advanced age and antiplatelet therapy, in the context of a high prevalence of cardiovascular disease in an elder population.

It is worth mentioning that only a small number of patients in this study are reported to use NSAIDs therapy, although this has been reported in other studies as an important cause of PPI therapy [19]. In fact, in the elderly, where the prevalence of osteoarticular disease is high, its 
use would be expected to be more prevalent than described. This underestimation may be explained by the omission of this therapy, since it is taken on demand and/ or without the need for medical prescription.

The indication for therapeutic PPI was present in slightly more than one-tenth of patients (11.8\% at admission and $13.5 \%$ at discharge), especially for GERD and dyspeptic symptoms. The dyspeptic symptomatology is also rarely mentioned in discharge letters and may justify some apparently unjustified PPI use. However, this is a short-term or on-demand indication and should not justify a long-term PPI use in the absence of other indications.

Nonetheless, possible omissions may reflect non-reassessment of the indication to maintain PPI therapy at discharge, which should be done routinely at this time (as with other pharmacological classes with poorer safety profiles). Hospitalization had little effect on the correction of prior outpatient prescription, which was demonstrated by similar percentages of inadequate prescription of PPI or failure to prescribe a PPI in the presence of a valid indication at admission and discharge. It was observed that it was more common to introduce PPI at discharge rather than suspend them, even in the absence of an indication to support their prescription. Such decision often results in a loss of association between the existence of PPI indication and its prescription.

We therefore emphasize the importance of reviewing PPI therapy according to valid indications in order to reduce polymedication, drug interactions, or adverse effects, as well as associated costs.
We hypothesize that an upper endoscopic study could help stratify the risk of patients whose previous history of ulcer was unknown. This would help defining the riskbenefit relation of antiplatelet/anticoagulant therapy and the need for PPI prophylaxis, since gastrointestinal bleeding may aggravate cardiovascular pathology, turning anticoagulants and antiplatelet drugs into aggravating factors for cardiovascular disease rather than preventive ones.

In conclusion, the study showed no relation between the indications for the use of PPI and its effective prescription. The primary indication for PPI therapy is the prophylaxis of gastrointestinal bleeding in high-risk patients, with a large proportion of these patients being discharged without prescription. The main inappropriate indication is the prophylaxis of gastrointestinal bleeding in low-risk patients. Hospitalization has a reduced impact on correcting prescription errors. A correct evaluation of the individual risk and revision of the indication for PPI at discharge should therefore be a priority.

\section{Statement of Ethics}

This study did not require informed consent nor review/approval by the appropriate ethics committee.

\section{Disclosure Statement}

Nothing to disclose.

\section{References}

1 Connelly D: The development and safety of proton pump inhibitors. Pharm J 2016.

2 Inibidores da bomba de protões (IBP). 2017. http://www.infarmed.pt. Accessed May 28, 2017.

3 Scarpignato C, Hunt RH: Nonsteroidal antiinflammatory drug-related injury to the gastrointestinal tract: clinical picture, pathogenesis, and prevention. Gastroenterol Clin North Am 2010;39:433-464.

4 Savarino V, Dulbecco P, Savarino E: Are proton pump inhibitors really so dangerous? Dig Liver Dis 2016;48:851-859.

5 Drugs@FDA: FDA Approved Drug Products. https://www.accessdata.fda.gov. Accessed April 19, 2017.
6 Gastro-oesophageal reflux disease and dyspepsia in adults: investigation and management - Guidance and guidelines - NICE. https://www.nice.org.uk. Accessed April 19, 2017.

7 NHS National Institute for Clinical Excellence: Guidance on the Use of Proton Pump Inhibitors in the Treatment of Dyspepsia. 2000.

8 Savarino V, Dulbecco P, de Bortoli N, Ottonello A, Savarino E: The appropriate use of proton pump inhibitors (PPIs): need for a reappraisal. Eur J Intern Med 2017;37:19-24.

9 Ladd AM, Panagopoulos G, Cohen J, Mar N, Graham R: Inappropriate use of proton pump inhibitors and its potential costs in low risk patients. Am J Med Sci 2013;347:1-6.
10 Batuwitage BT, Kingham JGC, Nia E, Morgan $\mathrm{R}$, Louise B: Inappropriate prescribing of proton pump inhibitors in primary care. Postgr Med J 2007;83:66-68.

11 Freedberg DE, Kim LS, Yang Y-X: The risks and benefits of long-term use of proton pump inhibitors: expert review and best practice advice from the American Gastroenterological Association. Gastroenterology 2017;152:706715.

12 Laine L, Nagar A: Long-term PPI use: balancing potential harms and documented benefits. Am J Gastroenterol 2016;111:913-915.

13 Lanza FL, Chan FKL, Quigley EMM: Guidelines for prevention of NSAID-related ulcer complications. Am J Gastroenterol 2009;104: 728-738. 
14 Yadlapati R, Kahrilas PJ: When is proton pump inhibitor use appropriate? BMC Med 2017; $15: 36$

15 Scarpignato C, Gatta L, Zullo A, Blandizzi C: Effective and safe proton pump inhibitor therapy in acid-related diseases - a position paper addressing benefits and potential harms of acid suppression. 2016;14.

16 Chia CTW, Lim WP, Vu CKF: Inappropriate use of proton pump inhibitors in a local setting. Singapore Med J 2014;55:363-366.

17 Scagliarini R, Magnani E, Praticò A, Bocchini R, Sambo P, Pazzi P: Inadequate use of acidsuppressive therapy in hospitalized patients and its implications for general practice. Dig Dis Sci 2005;50:2307-2311.
18 Pasina L, Nobili A, Tettamanti M, et al: Prevalence and appropriateness of drug prescriptions for peptic ulcer and gastro-esophageal reflux disease in a cohort of hospitalized elderly. Eur J Intern Med 2011;22:205-210.

19 Ahrens D, Chenot J-F, Behrens G, Grimmsmann T, Kochen MM: Appropriateness of treatment recommendations for PPI in hospital discharge letters. Eur J Clin Pharmacol 2010;66:1265-1271.

20 Tomizawa M, Shinozaki F, Hasegawa R, et al: Immunosuppressive agents are associated with peptic ulcer bleeding. Exp Ther Med 2017;13:1927-1931.
21 Hernandez-Diaz S, Rodríguez LAG: Steroids and risk of upper gastrointestinal complications. Am J Epidemiol 2001;153:1089-1093.

22 Conn HO, Poynard T: Corticosteroids and peptic ulcer: meta-analysis of adverse events during steroid therapy. J Intern Med 1994; 236:619-632.

23 Chrousos GA, Kattah JC, Beck RW, et al: Side effects of glucocorticoid treatment. JAMA 1993;269:2110.

24 Tsai C-F, Chen M-H, Wang Y-P, et al: Proton pump inhibitors increase risk for hepatic encephalopathy in patients with cirrhosis in population study. Gastroenterology 2016; 152:134-141. 